\title{
Mercury methylation and demethylation in paddy soil with and without rice plants
}

StRICKMAN, R.J. ${ }^{\text {* }}$, MARVIN-DIPASQUALE, M. ${ }^{2}$, MitChell, C.P.J. ${ }^{3}$, HuAnG, H. ${ }^{3}$, NeumanN, R.B. ${ }^{1}$

${ }^{1}$ Department of Civil and Environmental Engineering, University of Washington, Seattle, WA, 98119 (corresponding: strickma@uw.edu)

${ }^{2}$ United States Geological Survey, Menlo Park, CA, 94025

${ }^{3}$ Department of Physical and Environmental Sciences, University of Toronto, Scarborough ON M1C1A4, Canada

Methylmercury $(\mathrm{MeHg})$ is a neurotoxin that can accumulate in rice via uptake from the paddy soil into the plant. Mercury methylation and demethylation are microbial processes that control the concentration of $\mathrm{MeHg}([\mathrm{MeHg}])$ in paddy soil, although their relative influence may differ between vegetated and non-vegetated soils. This study is the first to assess potential rates of methylation and demethylation ( $\mathrm{K}_{\text {meth }}$ and $\left.\mathrm{K}_{\text {demeth }}\right)$ simultaneously in a manner that explicitly compares how they affect $[\mathrm{MeHg}]$ in the vegetated and non-vegetated paddy soil compartments. Flooded rice paddy soil microcosms (2x10x20") with and without rice plants were amended with enriched $\mathrm{Hg}$ stable isotopes $\left({ }^{200} \mathrm{Hg}\right.$ and $\left.\mathrm{Me}^{201} \mathrm{Hg}\right)$ to assess $\mathrm{K}_{\text {meth }}$ and $\mathrm{K}_{\text {demeth }}$. Overall, the results of this study suggest that $\mathrm{MeHg}$ concentrations are differentially controlled by $\mathrm{MeHg}$ production and degradation processes, depending on whether plants are present. In non-vegetated soils, $\mathrm{K}_{\text {meth }}$ was positively correlated with both ambient $[\mathrm{MeHg}](\mathrm{p}=0.02, \mathrm{r}$ $=0.90)$ and the percent of total $\mathrm{Hg}$ present as $\mathrm{MeHg}$ $(\% \mathrm{MeHg} ; \mathrm{p}=0.023, \mathrm{r}=0.87)$, while $\mathrm{K}_{\text {demeth }}$ had no relationship $(\mathrm{p}=0.77-79)$, indicating that $\mathrm{MeHg}$ formation drove $\mathrm{MeHg}$ dynamics. In planted soils, by contrast, $\mathrm{K}_{\text {meth }}$ did not correlate to $[\mathrm{MeHg}](\mathrm{p}=0.79)$. Rather, $\mathrm{K}_{\text {demeth }}$ was negatively correlated with both $[\mathrm{MeHg}]$ $(\mathrm{p}=0.04, \mathrm{r}=-0.82)$ and $\% \mathrm{MeHg}(\mathrm{p}=0.036, \mathrm{r}=-0.84)$, suggesting that degradation of $\mathrm{MeHg}$ was a more important control on the $[\mathrm{MeHg}]$ of vegetated soils. 